\title{
A system approach to improving maternal and child health care delivery in Kenyan communities and primary care facilities: baseline survey on maternal health
}

\author{
Ann Mwangi ${ }^{1}$, Mabel Nangami ${ }^{2}$, John Tabu ${ }^{2}$, David Ayuku ${ }^{1}$, Edwin Were $^{3}$, Esamai Fabian ${ }^{4}$
}

1. Moi University School of Medicine, Behavioural Science.

2. Moi University School of Public Health.

3. Moi University, School of Medicine, Reproductive Health.

4. Moi University, Child Health.

\begin{abstract}
Background: Maternal, fetal and neonatal mortality are 10 to 100 fold higher in many low-income compared to high-income countries. Reasons for these discrepancies include limited antenatal care and delivery outside health facilities.

Objectives: The study aimed at conducting a baseline survey to assess the current levels of maternal health indicators in six counties in Western Kenya.

Methods: This was a cross sectional study conducted targeting women residing in Uasin-Gishu, ElgeyoMarakwet, TransNzoia, Bungoma, Busia and Kakamega counties who had given birth five years prior to the interview. Socio-demographic and maternal indicators were collected using forms adopted from KDHS 2009. Interviews were conducted in the homesteads between December 2015 and June 2016.

Results: A total of 6257 women participated in the study, median age 27 years IQR 23-32. Majority of the women had post-primary level of education, were married and 40\% were members of an income-generating activity. $56.8 \%$ were using modern family planning method, 49\% attended WHO recommended four plus antenatal clinic visits and only $20 \%$ attended in the first trimester. Majority, 85\% had their most recent delivery in a health facility.

Conclusion: Findings suggest that women are not attending recommended four plus antenatal clinic visits and even those that attend are few are during the first trimester.

Keywords: System approach, maternal and child health care, Kenyan communities.

DOI: https://dx.doi.org/10.4314/ahs.v19i2.6

Cite as: Mwangi A, Nangami M, Tabu J, Ayuku D, Were E, Fabian E. A system approach to improving maternal and child health care delivery in Kenyan communities and primary care facilities: Baseline Survey on Maternal Health. Afri Health Sci.2019;19(2): 1841-1848. https:/ / dx.doi. org/10.4314/ahs.v19i2.6
\end{abstract}

\section{Introduction}

Despite decades of independence, most countries in sub-Saharan Africa are characterized by underperforming health systems in terms of low funding, operational and management inefficiency, poor quality of health services, inequities in distribution of the health workforce, and low capacity for planning, budgeting, and governance ${ }^{1}$. Ef-

\section{Corresponding author: \\ Ann Mwangi, \\ Moi University School of Medicine, \\ Behavioural Science. \\ Email: annwsum@gmail.com}

forts to improve the performance of these health systems are complicated by contextual factors such as intricate political landscape, unstable economic environment and rapid population growth. Some of the consequences of the weak health system include high maternal morbidity and mortality. Specifically, most countries in sub-Saharan Africa, with the exception of Rwanda, Ethiopia ,Malawi, Cape Verde and Tanzania did not meet MDG goals 4 and 5 because of weak health systems ${ }^{2}$. Maternal mortality reduction remains a priority under "Goal 3: Ensure healthy lives and promote well-being for all at all ages" in the new Sustainable Development Goals SDGs agenda through 2030 with special focus on indicators 3.1, 3.2 and 3.73. This is key to saving the lives of women who die due to complications from pregnancy and child birth.

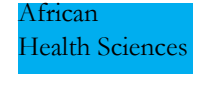

(C) 2019 Mwangi et al. Licensee African Health Sciences. This is an Open Access article distributed under the terms of the Creative commons Attribution License (https://creativecommons.org/licenses/BY/4.0), which permits unrestricted use, distribution, and reproduction in any medium, provided the original work is properly cited. 
Studies and reports from low and high income countries indicate that maternal, fetal and neonatal mortality are 10 to 100 fold higher in many low-income compared to high-income countries. The reasons for these discrepancies are many, but include the fact that many women and newborns receive little prenatal care and most deliver outside of health facilities that can provide lifesaving treatment for the mother, fetus and newborn ${ }^{4-6}$.

In low-income settings, maternal mortality ratios range from 150 to more than 1000 per 100,000 live births ${ }^{2}$ while rates of stillbirth and neonatal mortality generally range from 20 to 40 per 1000 births $^{7,8}$. Intrapartum stillbirth, or those stillbirths that occur during labor and delivery, are an important indicator of the quality of obstetric care ${ }^{9,10}$. While in high-income countries, intrapartum stillbirths have nearly been eliminated, in low-resource settings, up to half of all stillbirths occur in the intrapartum period9. Another measure of care is obstetric 'near miss' which has been defined by the World Health Organization WHO to comprise women who nearly died but survived a complication during pregnancy ${ }^{11}$.

Universal access to high quality facility care substantially reduces mortality and morbidity from these conditions ${ }^{12}$. Poor quality of antenatal care result in failure to detect and potentially refer these high risk pregnancies in lowand middle-income countries. This poor access to antenatal care and the obstetric complications contribute to high early neonatal deaths including still births ${ }^{13}$. In high-income countries, access to prenatal care is nearly universal.

In developing countries, most deliveries occur outside health facilities and by unskilled birth attendants ${ }^{14}$. In most health facilities, there is lack of equipment and drugs for basic obstetric, neonatal and child health care. In sub-Saharan Africa only between $20-70 \%$ of all births occur in health facilities, $5-15 \%$ of all newborns are resuscitated by a skilled health worker trained in neonatal resuscitation at time of birth and between $10-15 \%$ of these babies are born in facilities with resuscitation equipment ${ }^{15}$. Facility delivery is known to be the single most effective intervention for preventing maternal and neonatal morbidity and mortality. However, this is only true if there is quality of care at the facility. In Kenya, about $60 \%$ of deliveries occur in health facilities ${ }^{7,16}$.
The aim of the study was to conduct baseline survey on current levels of maternal health indicators including maternal mortality, compliance to ANC attendance and place of delivery in six counties in Western Kenya in relation to the national level as a prelude to the start of the quasi experimental study described elsewhere ${ }^{15}$.

\section{Methods}

We analysed data from a baseline survey carried out in six counties which were sampled purposively from eleven counties that Moi University frequently utilises for its health oriented outreach and extension activities. The six counties are UasinGishu, ElgeyoMarakwet, Trans Nzoia, Bungoma, Busia and Kakamega. Two of these purposively sampled counties Kakamega and Bungoma are among the eight counties with poorest maternal and child health outcomes ${ }^{17}$. The other counties used by the University not selected included Nandi, Baringo, West Pokot, Vihiga and Kisumu. One dispensary was randomly selected from each of the six selected counties from the list in the e-Health Kenya platform http://kmhfl.health.go.ke/\#/ home

All Women residing within the catchment population of the selected dispensary which is a location cluster headed by a Chief who met the inclusion criteria were recruited into the study.

The baseline survey was carried out from December 2015 to June 2016 by twelve research assistants who were residents in the six counties with an undergraduate degree in a health related or social science field. The assistants underwent a 5 day study specific training conducted by the research team. The training involved understanding the content of the questionnaires, and the consenting process. As part of the training they pre-tested the tools with healthy adult women at the Riley Mother Baby Hospital of the Moi Teaching and Referral Hospital.

Prior to data collection reconnaissance meetings were held in all the six counties to introduce the study and the team to the County Health officials as well as the facilities that were involved in the study. Community health volunteers, chiefs, and village elders mobilized the community members for the study prior to the data collection process. To facilitate community entry, the research assistants 
were accompanied by community health volunteers into the homesteads during the interviews. The interviews were conducted in the homesteads at the convenience of the participant.

\section{Study population}

The study targeted all women who had given birth five years prior to the interview or pregnant at the interview and were residing within the catchment population of the dispensary which is a location cluster headed by a Chief. In the present analysis, we included women residing in the cluster who had a child less than five years at the time of the interview. We excluded women who declined to give a written consent.

\section{Data management and analysis}

Data was collected using paper forms adopted from the KDHS 2014 questionnaire ${ }^{18}$ administered at the household level. The questionnaire consisted of two forms: $i$ Household questionnaire that collected data on: household composition e.g headship, size, age, marital status, education, membership in income generating activities and age at first birth ii) women questionnaire that collected data on e.g knowledge on family planning, fertility preference, antenatal and delivery care. The data was later entered in a password protected MYSQL database developed for data capture. The original paper forms were stored in a locked cabinet. Data were cleaned and exported to STATA version 13 for analysis that involved descriptive statistics to describe the social demographics and the level of maternal health indicators: family planning, ANC timing and number of visit, ANC tetanus toxoid coverage, ANC anaemia and Hypertension testing, facility/home delivery, admission duration post-delivery.

\section{Ethical considerations}

The proposal was approved by the MTRH/Moi University Institutional Research and Ethics Committee and the 6 County Health Management Teams (CHMTs). A written consent was obtained from all women enrolled into the study who accepted to participate. Those mothers who were minors age below 18 years, consent was sought from their guardians or husbands and assent from the minor. Illiterate eligible women had their thumb prints taken and the process was witnessed by an independent adult. The IREC guidelines on confidentiality on research among vulnerable groups were followed. Data confidentiality was ensured by password protecting the computer and ensuring that the data forms were stored under lock and key.

\section{Results \\ Demographic characteristics}

A total of 6257 women participated in the study. The contribution of the women identified from amongst the 6 clusters was variable based on the population density with Kakamega and Bungoma providing about 23\% each, Busia 20\%, Tran Nzoia 12\%, Uasin Gishu 17\% and Elgeyo Marakwet 5\%. Table 1 shows the characteristics of the participants. The participants had median age of 27 years interquartile range of 23-33 years. In terms of education, majority of the women had attained primary level and above with very few with no education $6.4 \%$. Majority of the women were married at the time of the interview, $(80 \%)$ with the lowest percentage reported in Uasin Gishu at $62 \%$. The mean number of children who were alive was $3.09 \mathrm{std}=1.82$ and the median age at first birth was 21 years IQR: 18-24 and didn't differ by county. Close to $40 \%$ of the women reported to be members of an income generating activity group. 
Table 1: Individual and household characteristics

\begin{tabular}{|c|c|c|c|c|c|c|c|c|}
\hline Variable & Transnzoia & UasinGishu & ElgeyoMarakwet & Bungoma & Busia & Kakamega & $\begin{array}{l}\text { Total } \\
\text { average }\end{array}$ & $\begin{array}{l}\text { National } \\
\text { estimates }\end{array}$ \\
\hline Age in years & & & & & & & & $25-29(37 \%)$ \\
\hline Median (IQR) & $26(22,30)$ & $30(27,36)$ & $29(25,35)$ & $27(23,32)$ & $27(23,32)$ & $27(23,32)$ & $27(23,33)$ & \\
\hline \multicolumn{9}{|l|}{ Highest level of } \\
\hline \multicolumn{9}{|l|}{ Education } \\
\hline None & $69(8.8)$ & $36(3.3)$ & $8(2.4)$ & $44(3.1)$ & $119(9.7)$ & $123(8.6)$ & $399(6.4)$ & 7.0 \\
\hline Primary & $238(30.4)$ & $214(19.8)$ & $155(47.6)$ & 533 (37.9) & $852(69.5)$ & $944(65.7)$ & 2936 (46.9) & 50.3 \\
\hline $\begin{array}{l}\text { Secondary/High } \\
\text { school }\end{array}$ & $323(41.3)$ & $514(47.6)$ & $126(38.7)$ & $525(37.4)$ & $200(16.3)$ & $285(19.8)$ & $1973(31.5)$ & 31.5 \\
\hline College/University & $153(195)$ & $315(29.2)$ & $37(11.3)$ & $304(21.6)$ & $55(4.5)$ & $85(5.9)$ & $949(15.2)$ & 11.2 \\
\hline Marital status & & & & 1217 & 1064 & & & \\
\hline Currently Married & 579 (73.9) & $665(61.6)$ & $255(78.2)$ & $(85.6)$ & $(86.8)$ & 1206 (83.9) & 4986 (79.7) & 54.6 \\
\hline Divorced/Separated & $54(6.9)$ & $78(7.2)$ & $3(0.9)$ & $22(1.6)$ & $18(1.5)$ & $24(1.7)$ & $199(3.2)$ & 7.7 \\
\hline Widowed & $6(0.8)$ & $42(3.9)$ & $5(1.5)$ & $23(1.6)$ & $14(1.1)$ & $11(0.8)$ & $101(1.6)$ & 3.7 \\
\hline Single & $107(13.7)$ & $264(24.5)$ & $59(18.1)$ & $84(5.9)$ & $102(8.3)$ & $146(10.2)$ & $762(12.2)$ & 28.9 \\
\hline Missing & $37(4.7)$ & $30(2.8)$ & $4(1.2)$ & $60(4.3)$ & $28(2.3)$ & $50(3.5)$ & 209 (3.3) & - \\
\hline \multicolumn{9}{|l|}{ Member of IGA } \\
\hline No & $424(54.2)$ & $598(55.4)$ & $177(54.3)$ & $467(33.2)$ & $924(75.4)$ & $1197(83.3)$ & 3787 (60.5) & - \\
\hline Yes & $359(45.8)$ & $481(44.6)$ & $149(45.7)$ & $939(66.8)$ & $302(24.6)$ & $240(16.7)$ & 2470 (39.5) & - \\
\hline \multirow[t]{2}{*}{ Age at first birth } & $\mathrm{N}=705$ & $N=1004$ & $N=307$ & $N=1247$ & $N=1129$ & $\mathrm{~N}=1277$ & $N=5669$ & \\
\hline & $22(19,25)$ & $22(20,25)$ & $20(18,23)$ & $20(18,23)$ & $20(18,24)$ & $20(17,23)$ & $21(18,24)$ & 20.3 \\
\hline \multicolumn{9}{|l|}{ Mean number of } \\
\hline children alive & 2.01 & 3.04 & 3.63 & 2.94 & 3.69 & 3.25 & 3.09 & 2.29 \\
\hline Number of women & 783 & 1079 & 326 & 1406 & 1226 & 1437 & 6257 & \\
\hline
\end{tabular}

\section{Maternal health indicators}

\section{Family planning}

Fifty seven percent of the women reported currently using family planning, with $56.8 \%$ reporting using a modern family planning method Table 2 . The main source of the modern family planning was a public facility Table 2 . Figure 1 shows the distribution of modern family planning across the six counties with the reference being the national estimate. From the plot, Busia reported a proportion lower than the national average while the other counties were above the national average.

Table 2: Family planning

\begin{tabular}{|c|c|c|c|c|c|c|c|c|}
\hline Variable & Transnzoia & UasinGishu & ElgeyoMarakwet & Bungoma & Busia & Kakamega & Total average & National estimates \\
\hline Currently using any & $489(62.5)$ & $606(56.2)$ & $168(51.5)$ & $924(65.7)$ & $569(46.4)$ & $812(56.5)$ & $3568(57.0)$ & 58.0 \\
\hline \multicolumn{9}{|l|}{ method } \\
\hline \multicolumn{9}{|l|}{ Currently using FP } \\
\hline None & $294(37.5)$ & $473(43.8)$ & $158(48.5)$ & $482(34.3)$ & $657(53.6)$ & $625(43.5)$ & $2689(43.0)$ & 42.0 \\
\hline Modern contraceptive & $487(62.2)$ & $604(56.0)$ & $167(51.2)$ & $918(65.3)$ & $568(46.3)$ & $807(56.2)$ & $3551(56.8)$ & 52.9 \\
\hline Traditional methods & $2(0.3)$ & $2(0.2)$ & $1(0.3)$ & $6(0.4)$ & $1(0.1)$ & $5(0.3)$ & $17(0.3)$ & 4.8 \\
\hline \multicolumn{9}{|l|}{ Source of modern FP } \\
\hline Public health facility & $395(81.1)$ & $456(75.5)$ & $149(89.2)$ & $883(96.2)$ & $532(93.7)$ & $765(94.8)$ & $3180(89.6)$ & 59.9 \\
\hline Private health facility & $55(11.3)$ & $89(14.7)$ & $9(5.4)$ & $6(0.7)$ & $18(3.2)$ & $14(1.7)$ & $191(5.4)$ & 33.7 \\
\hline Other & $32(6.6)$ & $48(7.9)$ & $2(1.2)$ & $1(0.1)$ & $9(1.6)$ & $22(2.7)$ & $114(3.2)$ & 5.9 \\
\hline Don't know & $5(1.0)$ & $11(1.8)$ & $7(4.2)$ & $28(3.1)$ & $9(1.6)$ & $6(0.7)$ & $66(1.9)$ & - \\
\hline
\end{tabular}




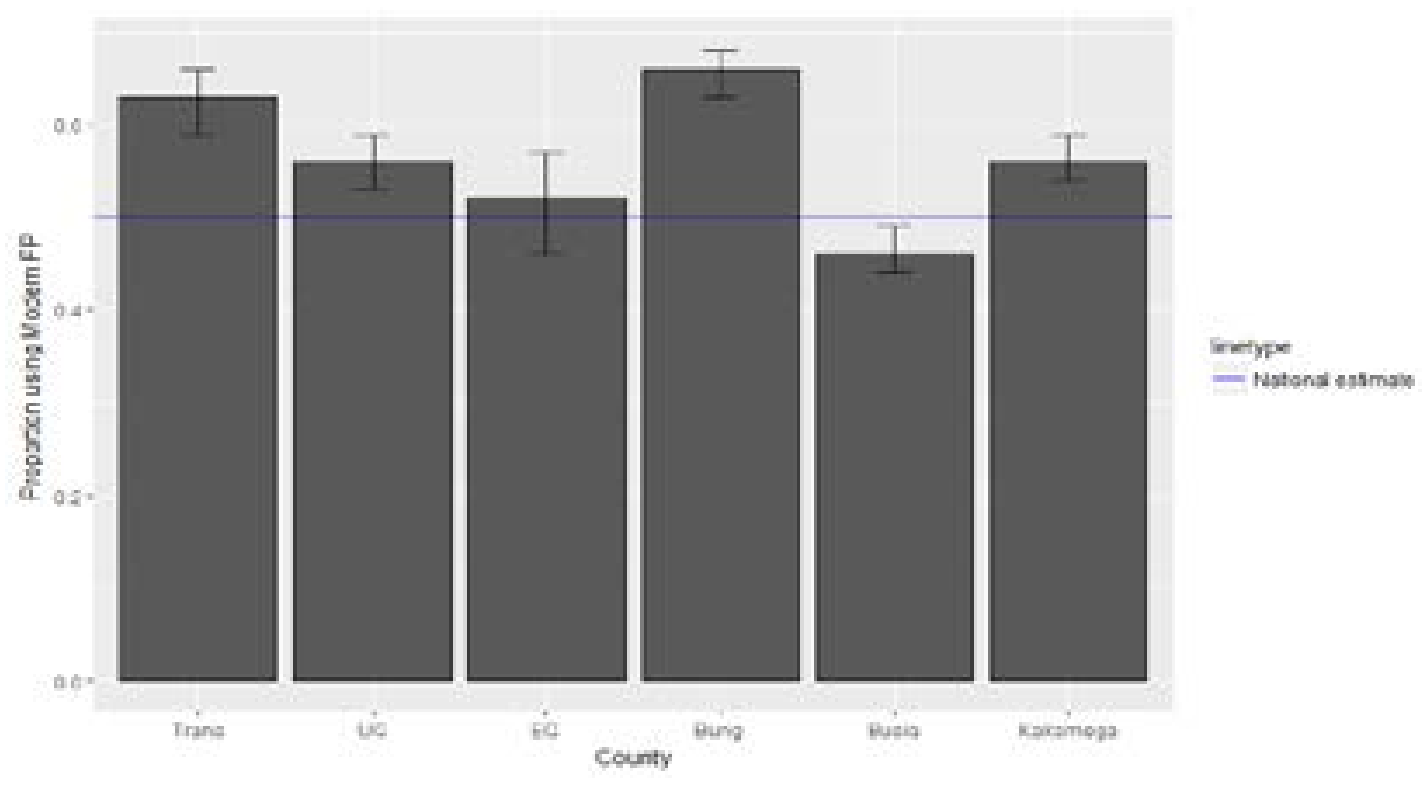

Figure 1: Use of modern contraceptives

\section{Antenatal care}

Results for antenatal care attendance as we all components offered during ANC are shown in Table 3. Ninety six percent of the respondents reported that women in their communities seek health services in public facilities when they are pregnant. Ninety eight percent indicated that pregnant women with complications are referred to public health facilities. Only $49 \%$ of the women made four or more of the recommended ANC visits for the most recent birth. Compared to the national estimates Figure 2 Uasin Gishu reported a very low proportion. In terms of timing only $20 \%$ reported a visit in the first trimester. 
Table 3: Antenatal care: attendance, timing and components

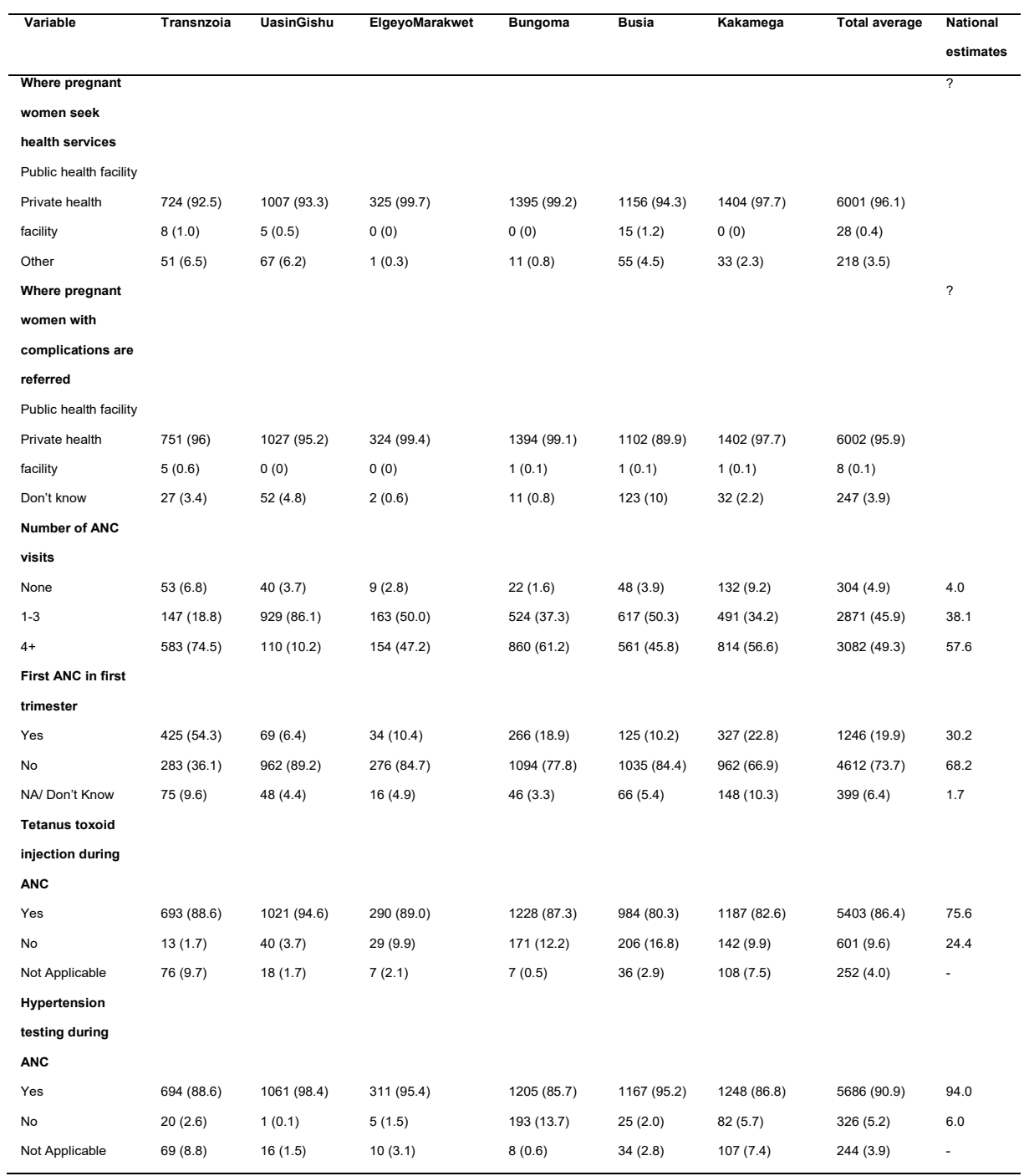

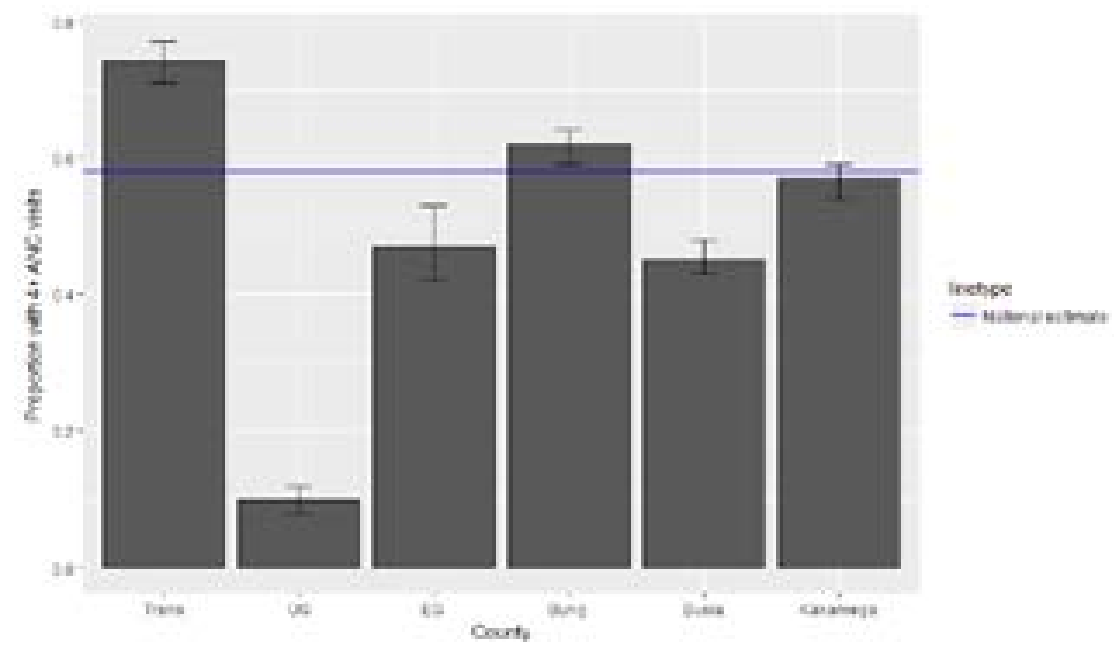

Figure 2: Proportion of women with more than 4 ANC visits 
Eighty-six percent of women had a tetanus toxoid injection during antenatal care for the pregnancy of their most recent birth. Ninety percent of women receiving ANC had their blood pressure measured and this didn't differ by county.

\section{Delivery and discharge}

More than 58\% participants reported that their most recent birth occurred in a facility which is slightly lower than the national estimate $61 \%$ and the average time of discharge was in less than 48 hours 55\% Table 4.

Table 4: Delivery and discharge

\begin{tabular}{|c|c|c|c|c|c|c|c|c|}
\hline Variable & Transnzoia & UasinGishu & Elgeyo & Bungoma & Busia & Kakamega & $\begin{array}{l}\text { Total } \\
\text { average }\end{array}$ & $\begin{array}{l}\text { National } \\
\text { estimate }\end{array}$ \\
\hline \multicolumn{9}{|l|}{ Place of last delivery } \\
\hline Facility & $401(51.2)$ & $613(56.8)$ & 209 (64.1) & 899 (63.9) & $632(51.5)$ & $864(60.1)$ & $3618(57.8)$ & 61.2 \\
\hline Home & $382(48.8)$ & $466(43.2)$ & $117(35.9)$ & $507(36.1)$ & 594 (48.5) & $573(39.9)$ & $2639(42.2)$ & 37.4 \\
\hline than 48 hours & & & & & & & & - \\
\hline Yes & $377(48.2)$ & $592(54.9)$ & $201(61.7)$ & $838(59.6)$ & $598(48.8)$ & $820(57.1)$ & $3426(54.8)$ & - \\
\hline No & $23(2.9)$ & $21(1.9)$ & $8(2.4)$ & $61(4.3)$ & $34(2.8)$ & $43(3.0)$ & $190(3.0)$ & - \\
\hline
\end{tabular}

\section{Discussion}

The work described in this paper addresses the findings of the baseline survey which is the first objective of the ongoing study. Attempts have been made to compare the findings of this survey to the national findings in the KDHS 2014 where appropriate.

Most of the characteristics of the study population are consistent with the national except for education level and marital status. In Busia county majority of the women had only achieved primary level of education. The proportion of women currently married was higher in all the surveyed counties compared to the national estimate as reported in the KDHS $2014^{18}$.

Family planning data for use of modern contraceptives is comparable to national figures with all the counties having higher rates of use of modern contraceptives than the national average except for Busia county.

The ANC attendance beyond the $4^{\text {th }}$ visit was higher than the national average for Trans Nzoia and Bungoma. This was however lower than the national average in the other 4 Counties with the Uasin Gishu showing the lowest proportion of women making more than $4 \mathrm{ANC}$ visits per pregnancy.

The World Health Organization recommends at least four ANC visits during a woman's pregnancy. First trimester timing of first ANC visit was very low in all the counties and much lower than the national estimates KDHS $2014^{18}$.

Evidence has shown that delivery in a facility with assistance by a skilled birth attendance reduced maternal and neonatal mortality ${ }^{19}$, due to improved emergency infrastructure, access to transport and referral facilities among other factors. Slightly more than half of the deliveries in the surveyed counties occurred in a health facility with assistance being provided by a skilled health worker which is lower than the national average.

The inclusion criteria for this study was women who had given birth in the last five years. With regard to family planning the issue of fertility preference wasn't addressed hence we might be underestimating current use of family planning because those not using might be planning to get pregnant which is a key limitation in this study.

The study documents the current inequalities in maternal health indicators in six counties despite the progress in reducing maternal and neonatal morbidity and mortality over the last 10 years. These inequalities form the basis for design of an innovative intervention Find-Link-TreatRetention $^{15}$. 


\section{Conclusion and recommendations}

The baseline findings of the study are similar to national estimates from the KDHS $2014^{18}$ with variations between the clusters.

Strategies of identifying pregnant women early in pregnancy need to be implemented to ensure that women seek services at the first trimester. This will also ensure that they make it for the recommended four plus ANC visits.

\section{Conflict of interest}

None declared.

\section{References}

1. WHO. Everybody's Business: Strengthening Health Systems to Improve Health Outcomes-WHO's Framework for Action. Geneva; 2007.

2. UNICEF. Committing to Child Survival: A Promise Renewed - Progress Report 2013. 2013.

3. United Nations. The Sustainable Development Goals Report. United Nations. 2016;

4. Goudar SS, Carlo W a, McClure EM, Pasha O, Patel A, Esamai F, et al. The Maternal and Newborn Health Registry Study of the Global Network for Women's and Children's Health Research. Int J Gynaecol Obstet. 2012;

5. Mavalankar D V, Rosenfield A. Maternal mortality in resource-poor settings: policy barriers to care. Am J Public Health. 2005;

6. Bauserman M, Lokangaka A, Thorsten V, Tshefu A, Goudar SS, Esamai F, et al. Risk factors for maternal death and trends in maternal mortality in low- and middle-income countries: A prospective longitudinal cohort analysis. Reproductive Health. 2015.

7. McClure EM, Pasha O, Goudar SS, Chomba E, Garces A, Tshefu A, et al. Epidemiology of stillbirth in low-middle income countries: A Global Network Study. Acta Obstet Gynecol Scand. 2011;

8. Oestergaard MZ, Inoue M, Yoshida S, Mahanani WR, Gore FM, Cousens S, et al. Neonatal mortality levels for 193 countries in 2009 with trends since 1990: A systematic analysis of progress, projections, and priorities. PLoS Medicine. 2011.
9. Goldenberg RL, McClure EM. Reducing intrapartum stillbirths and intrapartum-related neonatal deaths. International Journal of Gynecology and Obstetrics. 2009;

10. McClure EMM, Goldenberg RLL, Bann CMM. Maternal mortality, stillbirth and measures of obstetric care in developing and developed countries. Int J Gynaecol Obstet. 2007;

11. Pattinson R, Kerber K, Buchmann E, Friberg IK, Belizan M, Lansky S, et al. Stillbirths: How can health systems deliver for mothers and babies? Lancet. 2011;

12. Yakoob MY, Ali MA, Ali MU, Imdad A, Lawn JE, Van Den Broek N, et al. The effect of providing skilled birth attendance and emergency obstetric care in preventing stillbirths. BMC Public Health. 2011.

13. Manasyan A, Saleem S, Koso-Thomas M, Althabe F, Pasha O, Chomba E, et al. Assessment of obstetric and neonatal health services in developing country health facilities. Am J Perinatol. 2013;

14. Montagu D, Yamey G, Visconti A, Harding A, Yoong J. Where do poor women in developing countries give birth? a multi-country analysis of Demographic and health survey data. PLoS One. 2011;

15. Esamai F, Nangami M, Tabu J, Mwangi A, Ayuku D, Were E. A system approach to improving maternal and child health care delivery in Kenya: Innovations at the community and primary care facilities a protocol. Reprod Health. 2017;141.

16. Kenya National Bureau of Statistics KNBS; ORC Macro. Kenya Demographic and Health Survey 2008-09. Heal San Fr. 2010;

17. Summary Report of the Assessment of UNFPA's Advocacy Campaign to End Preventable Maternal and New-Born Mortality in Kenya. [cited 2018 Jul 16]; Available from: http://countryoffice.unfpa.org/kenya/2014/08/13/10333/counties

18. KDHS. Kenya Demographic and Health Survey 2014. Central Bureau of Statistics CBS [Kenya] Kenya Demographic and Health Survey. 2015.

19. Moyer C a, Dako-Gyeke P, Adanu RM. Facility-based delivery and maternal and early neonatal mortality in sub-Saharan Africa: a regional review of the literature. Afr J Reprod Health. 2013; 